\title{
Variables affecting the frictional resistance to sliding in orthodontic brackets
}

\author{
Mai AlSubie ${ }^{1}$ and Nabeel Talic ${ }^{2 *}$ \\ ${ }^{1}$ Orthodontic Specialist at Prince Sultan Armed Forces Hospital, Riyadh, Saudi Arabia \\ ${ }^{2}$ Department of pediatric Dentistry and Orthodontics, College of Dentistry, King Saud University, Riyadh, Saudi Arabia
}

\begin{abstract}
Friction in Orthodontics should be controlled during all stages of treatment, especially the space closure stage. If the friction resistance is high, slow progress and unnecessary elongation of the treatment time might result. Consequently, a practitioner must apply greater mechanical forces to overcome the frictional force progressively throughout the treatment. Friction is affected by physical and biological factors. The physical factors have been thoroughly studied in the literature. These physical factors are related to the bracket and arch wire properties and the ligation methods. The current knowledge on the subject is based on in vitro studies that, in most instances, produced conflicting results. This could be due to the inherent limitations of these studies as standardization of methods, or difficulty in simulating the oral environment and its effect on the surface characteristics of the materials used.
\end{abstract}

\section{Introduction}

Friction is defined as the force that retards the movement of two objects sliding against each other. As the two objects are moving against each other, two forces arises other than the initial force that generated the movement. The normal force is the applied force over the two objects pushing them into contact in a direction perpendicular to their surfaces, and the friction force is opposite to the direction of the movement force $[1,2]$. The friction force $(\mathrm{F})$ is proportional to the applied normal force $(\mathrm{N})$ multiplied by a constant, which is the coefficient of friction $(\varphi)$, such that $F=\varphi \mathrm{X} \mathrm{N}$. The coefficient of friction is a characteristic of each specific material. In orthodontics, examples of normal force components include the ligation force, which is the force of engaging a tooth that is out of the arch and the active torque in a rectangular arch wire. As these types of forces increase, the associated friction force also increases [3].

By definition, the two basic types of friction cannot coexist. The static friction is the force that exists between the contacting objects while they are at rest; it resists the initiation of the movement between the two objects. The sliding force has to build up to a maximum point overcoming the static friction force to let the sliding movement begin. Therefore, static friction is the one that needs to be overcome to commence the sliding movement. On the other hand, the kinetic friction arises after the movement has started between the two objects, and it needs to be overcome to maintain efficient movement [4]. In orthodontics, the static friction is more significant because tooth movement is not continuous. It consists of small increments of tipping and uprighting $[5,6]$. The investigators who measured both kinds of friction found the static friction value is almost always higher than the kinetic friction value $[7,8]$.

The term "friction resistance" is most frequently used to stand for the force resisting the sliding movement of the teeth. A more representable term is the resistance to sliding (RS), which can be divided into three phenomena: classic friction (FR), binding (BI), and notching $(\mathrm{NO})$, generally written as $\mathrm{RS}=\mathrm{FR}+\mathrm{BI}+\mathrm{NO}$. The classic friction occurs between the brackets and the arch wire when there is clearance between their surfaces. This happens when the arch wire is in a passive configuration inside the bracket's slot and no angulation exists. Binding occurs in the active wire configuration when the clearance between the wire and the bracket slot disappears, and the wire starts to bind against the bracket corners. The angle at which the FR no longer exists and the binding dominates the situation is called the critical angle $(\Phi)$. Notching happens when the sliding movement ceases by the presence of a permanent wire deformation at the bracketwire interface following a severe binding incidence [5]. During the sliding movement, the teeth experience different combinations of RS. The movement of the tooth is not continuous. Indeed, the cycles of the tooth movement begin with a crown tipping that leads to the binding of the brackets with the arch wires. Then, the periodontium surrounding the tooth reacts to initiate the root up righting along the direction of the applied force, allowing the translation of the tooth and the release of the bracket binding $[6,9]$.

\section{Importance of friction on orthodontics}

Because the force of friction impedes tooth movement, it should be controlled during all stages of orthodontic treatment, especially the space closure stage. If the friction resistance is high, slow progress and unnecessary elongation of the treatment time might result. Consequently, a practitioner must apply greater mechanical forces to overcome the frictional force progressively throughout the treatment. This is contrary to what is recommended in orthodontics about the use

Correspondence to: Dr. Nabeel F. Talic, BDS, MS, PhD, Associate Professor, King Saud University, College of Dentistry, Department of Paediatric Dentistry and Orthodontics, Saudi Arabia, E-mail: nftalic@yahoo.com

Key words: orthodontics, brackets, friction

Received: April 16, 2016; Accepted: May 12, 2016; Published: May 16, 2016 
of light forces to initiate and maintain tooth movement [5]. In addition to the biological parameters, the net moment to force ratio applied to the teeth is influenced by the magnitude of the applied force that was lost due to the frictional force. Consequently, this would impact the resultant centers of rotations $[10,11]$.

The loss of the applied force due to friction as reported in the literature ranges from $12 \%$ to more than $70 \%[5,12]$. Because friction force cannot be eliminated given that it is associated with every force applied to move the teeth, it should be controlled during the treatment. In this regard, two essential concepts should be considered. The frictional force should be kept as low as possible to maximize the force delivered to the tooth, and the frictional forces should be similarly maintained with each appliance activation. Therefore, the efficiency and reproducibility of the orthodontic treatment should be maintained [5]. Knowledge of bracket and wire material and the properties of each combination help in achieving these goals.

\section{Factors affecting friction}

Friction is a complex phenomenon that is multifactorial by nature. It is affected by physical and biological factors. The physical factors have been thoroughly studied in the literature. These physical factors are related to the bracket and arch wire properties and the ligation methods. The investigations of the biological factors are scarce due to their nature, and the difficulties associated with experimentally simulating them. These factors include the presence of saliva, plaque, and food particles.

\section{Arch wire properties}

To have efficient sliding movement in general and specifically during space closure, the working arch wire should have a low coefficient of friction. Arch wire material has been thoroughly investigated by many researchers. Vaughan et al. [13] found that stainless steel (SS) wires generate the least amount of friction, followed by cobalt-chromium (CO-Cr), nickel titanium wires (Ni-Ti), and beta-titanium ( $\beta$-Ti) wires. This is in agreement with multiple studies that found SS wires produce the least amount of friction compared with other alloys [14-16].

Investigations of the arch wire surface roughness indicated that the observed differences in friction might not necessarily reflect the surface roughness of the material. These studies showed that SS has the smoothest surface, followed by $\mathrm{CO}-\mathrm{Cr}, \beta-\mathrm{Ti}$, and $\mathrm{Ni}-\mathrm{Ti}$. This means that although $\beta$-Ti wires have smoother surfaces than $\mathrm{Ni}$-Ti wires, they are associated with more friction compared to Ni-Ti wires [17]. This finding of more friction associated with $\beta$-Ti wires is in agreement with several studies supporting that friction is highest with $\beta-\mathrm{Ti}[18,19]$. Kusy and Whitley [20] attributed this finding to the differences in surface chemistry and the affinity between the arch wires and the bracket couples rather than solely relying on the surface roughness of either the bracket or arch wire. The Kusy and Whitley [20] study indicated that the particles of $\beta$-Ti wires underwent chemical adhesion and mechanical abrasion by the stainless steel (SS) and polycrystalline alumina surfaces (PCA) ceramic brackets, respectively. Kusy and Whitley [20] also concluded that the worst couple for sliding mechanics was the $\beta-\mathrm{Ti}$ arch wire-PCA ceramic brackets due to the significant abrasion of the softer wire by the hardest bracket. Another study attributed the lowest friction values found in couples consisted of SS arch wires (regardless of the bracket type) to the accumulation of chromium oxide layers that rendered the surfaces chemically passive [21].

Another arch wire property that influences frictional resistance values are modules of elasticity that are characteristic of its stiffness. It appears that this property determines the behavior of the arch wire in the active or binding configuration inside the bracket slot. Studies have shown that $\mathrm{Ni}$ - $\mathrm{Ti}$ arch wires had a lower RS than SS wires at the binding configuration [22,23].

Regardless of the arch wire materials, the increase in the crosssection diameter has been associated with an increase in the frictional forces. This relation also applies to the changes in geometry of arch wire from round to rectangular. Therefore, it has been recommended to avoid larger sizes of the arch wire during the space closure stage [24,25].

\section{Bracket properties}

The majority of previous studies supported SS brackets as being the gold standard in terms of having less frictional properties compared to ceramic brackets $[8,26]$. Most of those studies attributed the high frictional properties of ceramic brackets to their rough surfaces. Concerns about nickel $(\mathrm{Ni})$ sensitivity led to the development of titanium (Ti) brackets. One study showed that Ti brackets had a coefficient of friction similar to SS brackets due to the formation of a passive layer of chromium and oxygen on the slot surfaces in both the passive and active wire configurations $[27,28]$. Another study showed that Ti brackets had a lower frictional resistance than SS brackets at a higher wire dimension $(0.017 \mathrm{X} 0.025 \mathrm{SS}$ wire in 0.018 slot brackets) [29]. Compared to the SS brackets, conventional plastic brackets were found to be associated with higher frictional resistance. When metal inserts were added to these brackets, their frictional characteristics were improved $[16,30]$. However, the inferior physical and chemical properties of plastic brackets, such as color changes and odor due to fluid absorption, preclude their use [5].

Along with bracket materials, bracket width has also been investigated as a factor affecting the bracket's frictional properties. However, the findings were conflicting. Some investigators found that the bracket width has little effect on frictional resistance [31]. Others reported that narrower brackets permitted a greater tipping, which could lead to increased angle interface between the arch wire and the bracket floor and more binding incidence $[1,9,32]$. They advocated wider brackets for better sliding mechanics because it allowed less tipping and less binding. It was also stated that the wider the brackets, the less moments will be needed to close the extraction spaces or to control the mesio-distal movements of the roots [1,9,32]. On the other hand, Kusy and Whitley [33] included bracket width in their attempts to derive the equation that determines the critical angle $(\Phi c)$. Kusy and Whitley [33] have concluded that the bracket width should be small to keep the contact angle during the sliding movement within the boundaries of the critical angle, where the binding phenomenon should start.

\section{Bracket-wire angulation}

Sliding tooth movement is more efficient when the bracket and the arch wire are in passive configuration, meaning there is clearance at their interface. In other words, the contact angle between the arch wire and bracket is less than the level of critical angulation, after which start the binding between the arch wire and the bracket corners [5]. There is consensus in the literature on the direct relation between the contact angle, or the similarly called second-order angulation, and the RS [8,19,26,34-38].

Kusy and Whitley [5] introduced the concept of dividing the RS into components such as classic friction, binding, and notching. The 
margins among these components depend on the amount of contact angle $(\Phi)$ between the wire and the bracket's floor. In the early stages of sliding, when the $\Phi$ either just or slightly exceeds the critical angle $(\Phi c)$, classical friction contributes more to the RS. In the intermediate stages, defined by having the $\Phi$ greater than the $\Phi c$, the binding dominates the RS. However, in the late stages, when the $\Phi$ is extensively beyond the $\Phi c$, notching of the arch wire occurs and the sliding movement is inhibited. The following work was devoted to determine the bounds of critical angulation in terms of nominal arch wires and bracket parameters. The following equation, from which the critical angle can be determined, was introduced based on the geometric analysis of the bracket-arch wire couple:

$$
\hat{O} c=\frac{57.32(1-(\text { Size } / \text { slot }))}{(\text { Width } / \text { slot })}
$$

The (size/slot) ratio defines the engagement index for the nominal arch wire, which defines the fraction of the bracket that is occupied by the wire size. The (Width/Slot) ratio defines the second important index, which means how many times the mesio-distal bracket width is larger than its vertical slot dimension. Using that formula, the practitioner can calculate the approximate value of the critical angle for specific bracket-arch wire couples. Considering the possible variability of bracket and arch wire dimensions during the manufacturing process and using a specific mathematical approach, Kusy and Whitley [5] concluded that the maximum value of $\Phi c$ is $4.5^{\circ}$. It was previously claimed that knowledge of the critical angle may save the clinician chair time by not over aligning the teeth before initiating sliding. It is sufficient for the bracket-wire contact angle not to exceed the critical angle for efficient sliding [39]. Articolo and Kusy [22] investigated the difference in RS between different bracket-wire couples at passive and active configurations. They concluded that in the passive configuration, the difference between the brackets was not significant. However, in the active configuration, all of the couples had a dramatic increase in RS values. They also noted that the binding component contributed rapidly to the RS. For example, in SS wire couples are at a $7^{\circ}$ angulation, the binding made up $94 \%$ of the RS and proportionally increased with the increase in the wire angulation [22].

\section{Methods of ligation}

Considering the law of friction, the friction resistance is proportional to the normal force that is applied perpendicularly over the two sliding objects and pressing them together. In the case of a bracket and an arch wire, the normal force is the force of ligation. The force of normal ligation was estimated to be from 50 gm-300 gm [40]. Several studies attempted to compare the ligation forces of SS and elastomeric ligatures to evaluate which of them would favorably be used during sliding mechanics. The results were controversial. Some of the studies demonstrated that loose SS ligatures were found to generate less frictional forces compared with elastomeric modules [37,41,42].

Matarese et al. [43] found no differences in the frictional forces between elastic ligatures and SS ligatures; however, the large standard deviation in the SS ligature group highlighted the difficulties in standardizing the force of ligation. In fact, several investigators reported that the force with which the SS ligatures should be tightened are difficult to define and the variation in force varied between $50 \mathrm{gm}-$ $300 \mathrm{gm}$ [44]. This could be the reason behind the controversy in the studies that compared the loose SS or tight SS ligatures with elastomeric ligatures. In addition to the difficulty in standardizing their forces for tightening, the SS ligatures were known to be time consuming [44].
Synthetic elastomeric ligatures were considered easier to apply, less time consuming, and more patient friendly than SS ligatures. However, they are made of polyurethane polymers, which are affected in their mechanical properties by moisture and the temperature of the oral cavity. Hence, many studies tried to simulate the oral conditions when testing the frictional or tensile properties. De Genova et al. [45] estimated the initial force of the elastomeric modules and after immersion in artificial saliva for 21 days. De Genova et al. [45] found that the initial force ranged between 241 gm-436 gm but decreased by $23 \%-37 \%$ after the incubation period. It was concluded that the remaining force was considered sufficient for tooth movement. Similarly, Taloumis et al. [46] reported a 50\%- $60 \%$ loss of the initial force during the first 24-hour interval in simulated oral conditions, and the decrease in the level of force continued at a lower rate for 7-10 days. However, they reported a residual force after 28 days for all the ligatures tested; this should hold an arch wire in a bracket slot.

Considering the effect of the force decay of elastomeric ligatures on their frictional characteristics, a previous study showed that immersion of elastomeric ligatures in artificial saliva for 21 days at $37^{\circ} \mathrm{C}$ caused a tensile force decay that varied from $51 \%-76 \%$ and a frictional reduction in the same proportion as the tensile force [47]. However, despite the agreement in the literature on the force decay of elastomeric ligatures with time, the associated frictional forces might not be affected in the same manner. Previous studies that tested the frictional resistance of elastomeric modules after in vivo storage for different periods found that frictional forces either increased or did not differ significantly compared to values obtained before the in vivo storage periods $[48,49]$. This result for the frictional forces was also found to be the case when the seating forces and the frictional forces were compared in SS and elastic ligatures. A previous study reported that the modules produced a significantly lower seating force than SS ligatures, while the opposite was true for the frictional forces. Therefore, the ligation force did not seem to correlate with the friction force. It was suggested that the surface characteristics of either SS or elastomeric ligatures might be more related to the friction forces than the physical ones [50]. This suggestion was also presumed by another study that evaluated two types of modules and found that their tensile properties were similar, although their frictional properties were significantly different [41].

An alternative approach in reducing the forces of ligation and the frictional forces was the ligature-free appliances, which are the selfligating brackets. Although these appliances were found to generate less frictional forces than the conventional brackets in specific conditions $[42,43,51]$, it was thought that in clinical settings, where binding occurs frequently with teeth tipping/up righting cycles, self-ligating brackets were not lower in RS than conventional brackets [32].

\section{Conclusions}

- The force of friction impedes tooth movement. The loss of the applied force due to the friction reported in the literature ranges from $12 \%$ to more than $70 \%$. Therefore, friction should be controlled and studied thoroughly during all stages of orthodontic treatment.

- Friction is a complex phenomenon that is multifactorial by nature. It is affected by physical and biological factors. The physical factors have been studied thoroughly in the literature. These physical factors are related to the bracket and arch wire properties and the ligation methods.

- Most of the current knowledge on the subject is based on in vitro studies that, in most instances, produced conflicting 
results. This could be due to the inherent limitations of these studies as standardization of methods, or difficulty in simulating the oral environment and its effect on the surface characteristics of the materials used.

- The term "friction resistance" is most frequently used to stand for the force resisting the sliding movement of the teeth. However, the term "resistance to sliding" (RS) is more appropriate, as it can be divided into three phenomena: classic friction (FR), binding (BI), and notching (NO).

\section{References}

1. Drescher D, Bourauel C, Schumacher H (1989) Frictional forces between bracket and arch wire. Am J Orthod Dentofac Orthop 96: 397-404. [Crossref]

2. Shames I (1998) Engineering Mechanics. Statics. Upper Saddle River N.J.: PrenticeHall.

3. Tidy D, Orth D (1989) Frictional forces in fixed appliances. Am J Orthod Dentofac Orthop 96: 249-254. [Crossref]

4. Bednar J, Gruendeman G, Sandrik J (1991) A comparative study of frictional forces between orthodontic brackets and arch wires. Am J Orthod Dentofac Orthop 100: 513-22. [Crossref]

5. Kusy R, Whitley J (1997) Friction between different wire-bracket configurations and materials. Semin Orthod 3:166-177. [Crossref]

6. Burrow S (2009) Friction and resistance to sliding in orthodontics: A critical review. Am J Orthod Dentofac. Orthop 135: 442-447. [Crossref]

7. Keith O, Kusy R, Whitley J (1994) Zirconia brackets: an evaluation of morphology and coefficients of friction. Am J Orthod Dentofac Orthop 106: 605-614. [Crossref]

8. Cha J, Kim K, Hwang C (2007) Friction of conventional and silica-insert ceramic brackets in various bracket-wire combinations. Angle Orthod 77: 100-107. [Crossref]

9. Omana H, Moore R, Bagby M (1992) Frictional properties of metal and ceramic brackets. J Clin Orthod 26: 425-432. [Crossref]

10. Braun S, Bluestein M, Moore B, Benson G (1999) Friction in perspective. Am J Orthod Dentofacial Orthop 115: 619-627. [Crossref]

11. Cattaneo P, Dalstra M, Melsen B (2008) Moment-to-force ratio, center of rotation, and force level: A finite element study predicting their interdependency for simulated orthodontic loading regimens. Am J Orthod Dentofac Orthop 33: 681-689. [Crossref]

12. Montasser M, El-Bialy T, Keilig L, Reimann S, Jäger A, et al. (2014) Force loss in archwire-guided tooth movement of conventional and self-ligating brackets. Eur J Orthod 36: 31-38. [Crossref]

13. Vaughan J, Duncanson M, Nanda R, Currier G (1995) Relative kinetic frictional forces between sintered stainless steel brackets and orthodontic wires. Am J Orthod Dentofacial Orthop 107: 20-27. [Crossref]

14. Angolkar P, Kapila S, Duncanson M, Nanda R (1990) Evaluation of friction between ceramic brackets and orthodontic wires of four alloys. Am J Orthod Dentofac Orthop 98: 499-506. [Crossref]

15. Kapila S, Angolkar P, Duncanson MG, Nanda RS (1990) Evaluation of friction between edgewise stainless steel brackets and orthodontic wires of four alloys. Am J Orthod Dentofac Orthop 98: 117-126. [Crossref]

16. Bazakidou E, Nanda R, Duncanson M, Sinha P (1997) Evaluation of frictional resistance in esthetic brackets. Am J Orthod Dentofac Orthop 112: 138-144. [Crossref]

17. Kusy R, Whitley J, Mayhew M, Buckthal J (1988) Surface roughness of orthodontic arch wires via laser spectroscopy. Angle Orthod 58: 33-45. [Crossref]

18. Saunders C, Kusy R (1994) Surface topography and frictional characteristics of ceramic brackets. Am J Orthod Dentofac Orthop 106: 76-87. [Crossref]

19. Nishio C, Da Motta F, Elias C, Mucha J (2004) In vitro evaluation of frictional forces between arch wires and ceramic brackets. Am J Orthod Dentofac Orthop 125: 56-64. [Crossref]

20. Kusy R, Whitley J (1990) Effects of surface roughness on the coefficients of friction in model orthodontic systems. J Biomech 23: 913-925. [Crossref]

21. Kusy R, Whitley J, Prewitt M (1991) Comparison of the frictional coefficients for selected arch wire- bracket slot combinations in the dry and wet states. Angle Orthod 61: 293-302. [Crossref]
22. Articolo L, Kusy R (1999) Influence of angulation on the resistance to sliding in fixed appliances. Am J Orthod Dentofac Orthop 115: 39-51. [Crossref]

23. Loftus B, Artun J, Nicholls J, Alonzo T, Stoner J (1999) Evaluation of friction during sliding tooth movement in various bracket-arch wire combinations. Am J Orthod Dentofac Orthop 116: 336-345. [Crossref]

24. Tanne K, Matsubara S, Hotei Y, Sakuda M, Yoshida M (1994) Frictional forces and surface topography of a new ceramic bracket. Am J Orthod Dentofac Orthop 106 273-278. [Crossref]

25. Reicheneder C, Baumert U, Gedrange T, Proff P, Faltermeier, et al. (2007) Frictiona properties of aesthetic brackets. Eur J Orthod 29: 359-365. [Crossref]

26. Williams C and Khalaf K (2013) Frictional resistance of three types of ceramic brackets. J oral Maxillofac Res 4: 1-7. [Crossref]

27. Kusy R, Whitley J, Ambrose W, Newman J. (1998) Evaluation of titanium brackets for orthodontic treatment: part I. The passive configuration. Am J Orthod Dentofac Orthop 114: 558- 572. [Crossref]

28. Kusy R, O'Grady P (2000) Evaluation of titanium brackets for orthodontic treatment: Part II--The active configuration. Am J Orthod Dentofac Orthop 118: 675-684 [Crossref]

29. Kumar B, Miryala S, Kumar K, Shameem K, Regalla R (2014) Comparative Evaluation of Friction Resistance of Titanium, Stainless Steel, Ceramic and Ceramic with Meta Insert Brackets with Varying Dimensions of Stainless Steel Wire: An in vitro MultiCenter Study. J Int oral Heal 6: 66-71. [Crossref]

30. Choi S, Kang D, Hwang CJ (2014) Surface roughness of three types of modern plastic bracket slot floors and frictional resistance. Angle Orthod 84: 177-183. [Crossref]

31. Frank C, Nikolai R (1980) A comparative study of frictional resistances between orthodontic bracket and arch wire. Am J Orthod 78: 593-609. [Crossref]

32. Burrow S (2010) Canine retraction rate with self-ligating brackets vs conventional edgewise brackets. Angle Orthod 80: 438-445. [Crossref]

33. Kusy R, Whitley J (1999) Influence of arch wire and bracket dimensions on sliding mechanics: Derivations and determinations of the critical contact angles for binding. Eur J Orthod 21: 199-208. [Crossref]

34. Ogata R, Nanda R, Duncanson M, Sinha P, Currier G (1996) Frictional resistances in stainless steel bracket-wire combinations with effects of vertical deflections. Am J Orthod Dentofacial Orthop 109: 535-542. [Crossref]

35. Read-Ward G, Jones S, Davies E (1997) A comparison of self-ligating and conventional orthodontic bracket systems. Br J Orthod 24: 309-317.

36. Redlich M, Mayer Y, Harari D, Lewinstein I (2003) In vitro study of frictional forces during sliding mechanics of "reduced-friction" brackets. Am J Orthod Dentofac Orthop 124: 69-73. [Crossref]

37. Thorstenson G, Kusy R (2003) Effects of ligation type and method on the resistance to sliding of novel orthodontic brackets with second-order angulation in the dry and wet states. Angle Orthod 73: 418-430. [Crossref]

38. Guerrero A, Guariza Filho O, Tanaka O, Camargo E, Vieira S (2010) Evaluation of frictional forces between ceramic brackets and arch wires of different alloys compared with metal brackets. Braz. Oral Res 24: 40-45. [Crossref]

39. Kusy R, Whitley JQ (1999) Assessment of second-order clearances between orthodontic arch wires and bracket slots via the critical contact angle for binding. Angle Orthod 69 : 71-80. [Crossref]

40. Jacobson A (1997) Biomechanic in clinical orthodontics. (1 $1^{\text {st }}$ edn.) Elsevier Inc: $457-$ 458.

41. Hain M, Dhopatkar A, Rock P (2003) The effect of ligation method on friction in sliding mechanics. Am J Orthod Dentofac Orthop 123: 416-22. [Crossref]

42. Kahlon S, Rinchuse D, Robison JM, Close JM (2010) In-vitro evaluation of frictional resistance with 5 ligation methods and Gianelly-type working wires. Am J Orthod Dentofac Orthop 138: 67-71. [Crossref]

43. Matarese G, Nucera R, Militi A, Mazza M, Portelli M, et al. (2008) Evaluation of frictional forces during dental alignment: An experimental model with 3 nonleveled brackets. Am J Orthod Dentofac Orthop 133: 708-715. [Crossref]

44. Iwasaki L, Beatty M, Nickel J (2003) Friction and orthodontic mechanics: clinical studies of moment and ligation effects. Semin Orthod 9: 290-297.

45. De Genova D, McInnes-Ledoux P, Weinberg R, Shaye R (1985) Force degradation of orthodontic elastomeric chains--a product comparison study. Am J Orthod 87: 377384. [Crossref] 
46. Taloumis L, Smith T, Hondrum S, Lorton L (1997) Force decay and deformation of orthodontic elastomeric ligatures. Am J Orthod Dentofac Orthop 111: 1-11. [Crossref]

47. Bortoly T, Guerrero A, Rached R, Tanaka O, Guariza-Filho O, et al. (2008) Sliding resistance with esthetic ligatures: An in-vitro study. Am J Orthod Dentofac Orthop 133: 340 e1-e7. [Crossref]

48. Dowling P, Jones W, Lagerstrom L, Sandham J (1998) An investigation into the behavioral characteristics of orthodontic elastomeric modules. Br J Orthod 25: 197 202. [Crossref]
49. Edwards I, Spary D, Rock W (2012) The effect upon friction of the degradation of orthodontic elastomeric modules. Eur J Orthod 34: 618-624. [Crossref]

50. Khambay B, Millett D, McHugh S (2005) Arch wire seating forces produced by different ligation methods and their effect on frictional resistance. Eur J Orthod 27: 302-308. [Crossref]

51. Cacciafesta V, Sfondrini M, Ricciardi A (2003) Evaluation of friction of stainless steel and esthetic self- ligating brackets in various bracket-archwire combinations. $A m J$ Orthod Dentofac Orthop 124: 395-402. [Crossref]

Copyright: (C2016 Subie MA. This is an open-access article distributed under the terms of the Creative Commons Attribution License, which permits unrestricted use, distribution, and reproduction in any medium, provided the original author and source are credited. 